\title{
A Comparative Study on Chinese and English Animals Idioms and Translation Strategies
}

\author{
Jili Liu \\ Shanxi Normal University, China
}

\begin{abstract}
Idiom, being an indispensable constituent of language, is the quintessence of the erudition. Every civilization has its own characteristics on the ground that there are some discrepancies in history, geography, customs, etc., among divergent sovereign states. Therefore, it is unambiguous that there subsists divergences in metaphorical objects and its implication of animal idioms among distinctive erudition. This paper attempts to compare and contrast English and Chinese animal idioms from its metaphorical objects and meanings and they can be categorized into four types. It is widely acknowledged that some animal idioms have equivalent connotations in culture. However, the majority of them have diverse implications among distinctive countries. On this basis, many exemplars are cited to make clear translation strategies of Chinese animals idioms. The author will interpose several interpretation principles a. Equivalent Translation, Reserve Image; b. Corresponding Translation, Change Image; c. Compromising Translation, Abandon Image. The author expects these translation principles will provide some constructive clues for translators. Here the author will mainly illustrate the translation strategies of idioms that have same metaphorical objects and maintain different metaphorical meanings as well as idioms of metaphorical vacancies on the basis of the comparative study on Chinese and English Animals idioms.
\end{abstract}

Index Terms - animal idioms, metaphorical objects, metaphorical meaning, equivalent translation, reserve image, compromising translation, abandon image

\section{INTRODUCTION}

Significance of This Research: This paper is about translation strategies of Chinese animals idioms based on comparative study on C-E animals idioms in a comprehensive way. The principles of interpretation idioms are consequential for the distribution of erudition and mutual correspondence in intercontinental dissemination.

In this paper, translation strategies can be sorted into three types: a. equivalent translation, reserve image; $b$. corresponding translation, transform image; c. compromising translation, abandon image. The author will predominantly make clear the rendering strategies of animal idioms that have same metaphorical objects and maintain divergent implicit implications as well as idioms of metaphorical vacancies on the basis of the comprehensive inquiring on animals idioms in different countries from its metaphorical objects and its connotations. Hence, the technique of interpretation is connected to foreignization and domestication.

The research is contributive only to foreign readers to come realize still more fully the momentousness of acquiring Chinese culture. Furthermore, individual's outlook towards animals idioms will have a dramatic change as well as guide students in rendering these culture-loaded animal idioms.

Structure of This Paper: This paper embrace three constitutes apart from the presentation and corollary component.

Part one gives a full picture of idioms which are the quintessence of not languages but civilization. In C-E interpretation, idioms are the most intricate and entangled part to explicate. This part first discusses the definition of idioms, interpreting the complexion of animal idioms to promote individual have a better perception of idiom translation.

After conversing the clarification and features of idioms, part two circumducts around a comparative study on animals idioms from its metaphorical objects and meanings. These animal idioms can be docketed into four forms: First, similar implicit objects, similar connotation; Second, divergent implicit objects, similar implicit meaning; Third, same implicit objects, different implicit implications; Forth, implicit vacancies.

Part three focuses on methods of animal idioms in Orient translation and the gist that should be attached great significance in the process of rendering Chinese animal idioms into English.

Finally, the author draws a ending and makes a sweeping assumption of the whole paper condensedly, offering her perspective and figuring out the achievements and drawbacks of the research about the translation of Chinese animals based-on a comparative inquiring of animal idioms in different culture in a comprehensive way.

Former Studies on Animal Idioms at Home and Abroad:

The studies on animal idioms at abroad: There is quite a little information that can be acquired about the study of animal idioms in western countries. It is universally reckoned that the study of animals idioms is initiated by L.P. Smith. (1957), an American-based British essayist and critic. In his book Words and Idioms: Studies in the English Language, he divided the sources of idioms and stressed that the connections of an idiom is not merely the union of all words in the idiom. However, he rarely debunks the features of idioms. 
The studies on animal idioms at home: In the process of studying animal idioms, scholars in China study the associative meaning of domestic animals that have intimate connections with animals in western culture. Li Yuping (2008) analysis the associative meaning of animal idioms and offers some examples in his work "English Idioms and Their Cultural Origin". There are mainly C-E comparing and contrasting method, metaphor cognition method, context learning method, and translation contrast method in inquiring animal idioms. Deng Yanchang, Liu Runqing (1991) compile the book "Language and Culture". Both of them have used comparative methods to study the connotation of animal idioms.

\section{CHINESE AND ENGLISH IDIOMS}

An idiom is a suit of words with an intrinsic implication divergent from the connotations of its component words. Besides, there exists a dramatic divergence between its intrinsic and literal implication, e.g. "black sheep" (害群之马), "I'm all ears" (洗耳恭听).

Idioms are avowed as the core of a language, which is the long-term achievements of people's wisdom and the reflection their particular circumstances.

Idioms embody the core a civilization and provide a vivid picture of the people and their life experience as well as culture. Therefore, the author starts from its definition and features of animal idioms to have a full understanding of them.

\section{A. Explication of Idioms}

The word "idiom" initiates from the Greek word "idio", which refers to private and specific. An idiom is a suit of words whose substance is distinctive from the connotations of the individual words, which is the explanation by Hornby (1997) in Oxford Advanced Learner's English-Chinese Dictionary.

Hence, an idiom is characterized by a set of phrases or a sentence with the denotations distinctive from the literal one and should be committed to memory as a complete. The implication of “成语” is that they are definite sentences or phrases which are compendious in forms and integrated in connotation, and has been refined through epoch of formula. In Chinese, there are a series of four-character structure animal idioms, some of which is not at all difficult to understand from its surface, for example:

“后来居上”(the later comers surpass the old timers); “杯弓蛇影” (be extremely suspicious);“朝三暮四”(blow hot and cold; chop and change); (Hui, 2004, p. 2016 )

To sum up, an idiom may be exemplified as a compound of two or more words which are structurally settled and semantically amphibological, and perform as a sole layer of connotation. It is an established form that has already been accepted by conventional habitude.

\section{B. Characteristics of Idioms}

Idioms distinguish themselves from other general expressions and structures by its own distinctive characteristics.

1. Semantic Integrity

A idiom is an establish form of words or a phrase, therefore, it should be regarded as whole and cannot be categorized into smaller part or an individual word, extra they would presumably be completely misunderstood.

Literally, we may get confounded if demonstrating the idiom or phrase word by word. For example "rain cats and dogs". Its connotative meaning has nothing to do neither with "cats" nor "dogs", which, indeed, signifies pouring rain. We cannot understand the meaning of the idiom correctly by the union of separate implication of the words, as well as it must needs to be reckoned to be a complete.

2. Stability in structure

Stability in structure signifies the words in idiom could not be deleted, added to or replaced by synonyms, or put in a divergent lineup, without destroying or transforming the implication of the idiom. The author intends to give some exemplifications to demonstrate this subject matter.

Taking the Chinese animal idiom “对牛弹琴” for instance. In English, we can convey the meaning of the idiom by saying cast peals before a swine, instead of pearls are cast before a swine, or cast peals before pigs. In Chinese, we invariably say “对牛弹琴”, instead of “弹琴给牛听” or “对猪弹琴”.

3. Metaphorical in meaning

Metaphors and idioms are closely associated with each other, and in fact most idioms are based on metaphor, e.g., “狐 朋狗友” contrasts “狐” and “狗” in a metaphorical way, we all know that it's not really refers to real “foxes” or “dogs”, instead it means evil associates.

\section{A COMPARATIVE STUdy On CHINESE AND ENGLish ANIMALS IDIOMS}

According to metaphorical objects or animal apply in animal idioms, which would be incorporated into four varieties: First, similar implicit objects, similar connotations.

Second, different implicit objects, similar implication.

Third, same metaphorical objects, different metaphorical meanings. 
Forth, Metaphorical Vacancies.

\section{A. Same Metaphorical Objects, Same Metaphorical Meaning}

There are a multitude idioms in Sino-Western countries, which share the similar objects and show the similar or same connotation. After a meticulous judgmatic, here the author makes clear the animals idioms in this paper.

Taking the animal fox as an example. Both Chinese and English surmise fox as being guileful. In English, fox signifies (invariably uncomplimentary) a person who is canny and boasts the capability to get what they want by compelling or deluding other people which derives from Oxford Advanced Learner's English-Chinese Dictionary by Hornby (1997). The animal old fox (老狐狸) exactly comes to the point. There are also a multitude of idioms about fox in Chinese culture, such as

“狐朋狗友” (evil associates); “狐群狗党”(pack of rogues);“狐疑不决”(wavering and unable to decide); “狐梅惑 主”(entice one's master by coquettish charms) (Hui, 2004, p. 668).

Moreover, individuals in distinctive culture are likely to evoke same or similar associations towards same animal. In English, a parrot a animal that repeats what someone else has said without thinking about what it means,such as "parrot one's words” (Hui, 2004, p. 1950). In Chinese, there is “鹦武学舌” which simplifies to repeat other people's words like a parrot.

Besides, both Chinese and westerners regard an bee as busy and industrious, a sheep or a lamb as being timid and docile, such as “羊入虎口” referring to a sheep in a pack of wolves---be in imminent danger of death (Hui, 2004, p. 1877);““羊质虎皮”referring to pretend to be formidable but indeed timid (Hui, 2004, p. 1877).

\section{B. Different Metaphorical Objects, Same Metaphorical Meaning}

With the evolvement of human cultivation, all nations' culture is converged to a degree. However, it doesn't mean the loss of cultural divergences.

On the contrary, the fulfillment of the humanity is becoming increasingly picturesque and various, which reflects the implicit objects applied in animal idioms. When expressing the similar implicit meaning, animal idioms tend to adopt divergent kinds of animals as their implicit objects, that is to say, divergent kinds of animal idioms demonstrate similar cultural connotations and connotations. Examples are as follows:

Chinese Idioms English Idioms

$\begin{array}{ll}\text { 一箭双雕 } & \text { to kill two birds with one stone } \\ \text { 胆小如鼠 } & \text { as timid as a hare/rabbit } \\ \text { 狐假虎威 } & \text { an ass in a lion's skin } \\ \text { 害群之马 } & \text { black sheep } \\ \text { 如鱼得水 } & \text { like a duck in water } \\ \text { 狼吞虎咽 } & \text { eat like a horse } \\ \text { 瓮中之鳖 } & \text { a rat in a hole } \\ \text { 骑虎难下 } & \text { hold a wolf by its ear } \\ \text { 非驴非马 } & \text { neither fish nor foul } \\ \text { 打草惊蛇 } & \text { to wake a sleeping dog } \\ \text { 瓮中之鳖 } & \text { like a rat in a hole } \\ \text { 对牛弹琴 } & \text { to cast peals before swine } \\ \text { 画蛇添足 } & \text { to paint the lily }\end{array}$

\section{Same Metaphorical Objects, Different Metaphorical Meanings}

The same animal may associate with different metaphorical connotations in divergent regions on account of divergences in cultural backgrounds, customs and the like.

The implicit meanings of some English animal idioms are commendatory, while its corresponding animal idioms in Chinese are neutral or even derogatory. "Dog" and "dragon" are prototype in point. When it come to "dog", both countries have a totally different attitude to dog.

In western counties, dog is considered as human's friend and it symbolizes companion and friendship or even family member. Thereupon, most English idioms concerning dog are complimentary, such as, "lucky dog”(幸运儿); “Every dog has its day”(人人皆有得意日); “love me, love my dog”(爱屋及乌).

Dog has uncomplimentary implication, which it is adequately designated in some animal idioms. For instance, "let sleeping dogs lie"(别惹事生非); “a dead dog”(废物); “dog eat dog”(自相残杀).

However, people still treat it as their good friends in western culture. A multitude of Chinese animal idioms with dog are derogatory in Chinese culture. For instance, “狗眼看人低”(be damned snobbish); “狐朋狗友”(evil associates; disreputable gang); “狗䒨不如”(of a person his behavior be contemptible mean); “狗仗人势”(be a bully with the backing of a powerful person); “人模狗样”(look decent or behave decently; pretend to be a person of worth); “狼心狗 肺”(someone who are cruel and unscrupulous/brutal and cold-blooded) (Hui, 2004, p. 570). 
One more archetype is “dragon”. Many English idioms about dragon are associated with loathsome or even baneful things. For example, “the old dragon”(魔鬼); “chase the dragon”(吸食海洛因); “sow dragon’s teeth”(挑起斗争，激化 矛盾).

Howbeit, dragon represents power in Orient and idioms contain the character “龙” invariably express someone's good wishes. Examples are as follows:“龙潭虎穴”(dangerous place); “龙马精神”(vigorous spirits of people); “龙腾虎 跃”(scene of hustling and bustling activity); “攀龙附凤”(play up to people of power and influence); “望子成龙”(expect one's son win success in the world);“画龙点睛”(add a touch that brings a work of art to life); “蛟龙得水”(get the good opportunity to display one's talent); “云起龙骧”(great men come to the fore when opportunity offers);“龙凤呈 祥”(the union of a dragon and a phoenix foretells good fortune). (Hui, 2004, p. 1025).

\section{Metaphorical Vacancies}

Owning to divergences in culture background, customs, living condition, ways of thinking, aesthetic values, life experiences and the like. Some animals perhaps have a metaphorical meaning in a language, but it doesn't exist in another language. Moreover, some animals may live in one locality or country, while they cannot be caught sight of in another.

In western culture, there are some idioms with animals that have implicit meanings that don't come into existence in Chinese culture. For instance, it is well-know that butterfly is merely an ordinary animal in Chinese and doesn't boast special associative meanings. The Chinese people will guess the literal implication of this idiom "to have butterflies in one's stomach".

However, they may not have the image that would provoke anxiety to individuals in western countries. Therefore, they couldn't appreciate the vividness of the idiom.

Beaver is the second largest living rodent in the nature which is next to the capybara, and is known for its engineering feats, but Chinese know little of it. Beavers have unique technique and capability for creativity and they are hard-working animals. They are very busy animals, and they gnaw all day fabricate their dwellings Therefore, the idiom "work like a beaver" refers people who work very hard in western culture; "eager beaver" means someone who is very enthusiastic or works very hard", which has a slightly disparaging connotations in some particular situations. However, in most Chinese people's perspective, beaver is merely an unfamiliar animal without any implication.

In Chinese people's mind, the animal “乌龟”, whose English name is tortoise. On the one hand, it stands for longevity because it is extremely long-lived. Another is that it simplifies "foolish people". While it doesn't have such associative implications in western countries, and it's merely an animal which moves very slow. In Chinese the animal “鹗茑”, whose English name is mandarin duck, usually signifies a sympathetic couple, but it doesn't have any implicit meanings in western countries. In Chinese the animal “雁”, whose English name is swan goose, is invariably associate with letter, and the idiom “鸿雁传书” means “a letter delivered by swan geese, letters from afar” (Hui, 2004, p.661). However, the swan goose doesn't have such or any cultural connotations.

\section{Translation Strategies of Chinese Animals IDIOM}

Since humanity live in a common objective world, and experiencing almost similar civilization history, therefore, there are some similarities among different human civilizations, which are the foundations and prerequisites for cultural exchange and diffusion of knowledge. However, one civilization remarkably differs from the other. Every civilization has its own characteristics on the ground that there are some differences among different countries or nations.

\section{A. Translation Methods of Animal Idioms}

It is one of the most distinguishing symbols of native speaker or non-native speaker to have a good master of a wide range of idioms and have the capacity to adopt them in the context. Undoubtedly, translation is full of challenges and is no longer a light work, supremely the interpreting of idioms.

In general, three strategies are possible in translating animal idioms, and they are respectively the equivalent translation, reserve image; corresponding translation, change image; compromising translation, abandon image. In the paper the author will mainly make clear the translation strategies of animal idioms that boast similar metaphorical objects and maintain divergent metaphorical implications as well as idioms of metaphorical vacancies. In addition, Chinese animal idioms of metaphorical vacancies can apply compromising translation and abandoning image to interpret.

\section{B. Translation Idioms of Same Metaphorical Objects and Different Metaphorical Meanings}

Chinese idioms are consists of many characters, such as “前有猛虎, 后有豹狼”, “前怕狼后怕虎” but idioms are usually composed of four characters, such as “狼狈为奸”, “如鱼得水”, “指鹿为马”, “胆小如鼠”, “一丘之貉”, and “对牛弹琴”. This four-character structure is very peculiar in Chinese, and some these idioms are often closely associated which historical events. In C-E translation, animal idioms with four-character can't be rigidly translated into four English words, and therefore translators should dig beneath the surface and grasp the implicit meaning of animal idioms to conceive the meaning and implication of the animal idioms comprehensively. 
Each kind of idioms has respective ways of interpretation approach. The Chinese idioms, which have same metaphorical objects and different implicit meanings, can be interpreted by the following methods: a. equivalent translation, reserve image; b. compromising translation, abandon image.

1. Equivalent translation with reserving of image

Equivalent translation also manifests literal translation, which signifies an adequate representation of the original. It puts more emphasize on preserving the originality of source language. Literal translation, also called direct rendering or word-for-word rendering which is a translation strategy that is frequently took advantaged in the process of translating. It strives to conserve the peculiarity of original literary work in a large extent.

1) “宝姐姐, 你还不拧他的嘴？你问问他编排你的话!”宝钗笑道: “不用问，“狗嘴里还有象牙不成”!”(Cao, 2012)

“Pinch her lips, Chai!"she said."You should hear what she's been saying about you."“I don't need to,”said Bao Chai."One doesn't expect ivory from a dog's mouth!"

Idiom “狗嘴里还有象牙不成” describes a filthy mouth can’t utter decent words.

The translator adopts literal translation strategy on the whole to put across cultural implication or ideas of the original text in translating the idiom.

Animal idioms are pervaded by cultural characteristics, and dog is a humble animal in the Orient. Moreover, anything related to dogs are mostly negative, and ivory is very valuable.

Nevertheless, people in foreign nations, particular western countries, invariably look upon dogs as their familiar, and $\operatorname{dogs}$ are of an importunate fraction of their daily life. Though such translation doesn't interpreting the cultural implication of the animal idiom, there is no doubt that readers don't have any difficulty in apprehension the animal idiom on the ground that the implication of this animal idiom is quite apparent and perceptible within the context.

The idiom reserves the metaphorical objects "dog's mouth" and "ivory", which passes on the vividness of animal idioms in Orient to foreign readers and conserves the original flavor of Chinese culture in a large extent. It keeps the original culture favors and conveys the meaning of the idiom.

2) 李先生恨不能身外化身, 拍着自己肩膀, 说:“老李, 真有你!”所以也不谦虚说: “我知道这种女人路数多, 有 时用得着她们, 这就是梦尝君结交鸡鸣狗盗的用意。”(Kelly\& Mao, 2003, p. 159)

$\mathrm{Li}$ wished he could have jumped out of his body and patted himself on the shoulder, saying, "Li, ol'boy, you really are something!" He then bragged openly, "1 know that sort of women have many of their own special ways of doing things and can sometimes be useful. That's what Meng Ch'ang-chun had in mind when he befriended men who could crow like a cock or steal like a dog."

The connotative point of the animal idiom is that people who resort to petty tricks, which literally means that the malevolent individual who crow like a cock and snatch like a dog. Numerous animal idioms related to dogs contain uncomplimentary meaning in Chinese, and is employed to particularize baneful individuals or things. While it is considered as loyal and reliable friend as well as partner in western nations.

Although the authors keep the original image of "crow" and "dog", they don't refer to the real animals. Moreover, the authors add the word "men" to make the implication of the sentence concrete and apparent, they bring to bear both domestication and foreignization to interpret this animal idiom. This translation version conforms to the principles of rendering and the translation is supposed to interpret the idea of the original works thoroughly, come up with by Alexander Fraser Tytler.

It is also in accordance to the Triple Principle of Translation, faithfulness, expressiveness, elegance put forward by Yan Fu. The translator should have embrace a variety of interpretation strategy and take many factors into consideration in translating animal idioms.

3) “原来这学中虽都是本族人丁与些亲戚家的子弟, 俗话说的好, “一龙生九种, 种种有别”, 未免人多了, 就有 龙蛇混杂，下流人物在内” (Cao, 2012)

"Now although all the people in this school were members of the China clan or relation by marriage, as the proverb aptly says, "A dragon begets nine offsprings; each one different." And inevitably among so many boys there were low types too, snakes mixed with dragons." (Zeng, 2007)

The idiom literally means dragons and snakes jumbled together.

The connotation of the idiom in the context is that the virtuous and the unvirtuous are mingled together. The translator's translation, however, can't make clear the meaning of the idiom by using direct translation without further interpretation in the process of rendering the idiom. Because of cultural differences, people in different countries hold totally opposite attitude towards the animal“龙”, which is called "dragon” in English speaking countries.

Therefore, such interpretation is quite inappropriate. In Chinese, dragon assumes the role of distinguished and preeminent individual, and Chinese people invariably name themselves as “龙的传人”, whose literally means descendants of the dragon, while dragon signify evil thing or vicious people.

The animal snake boasts the same connotative meaning both in Chinese and western culture. It cannot inform the target readers of what the idiom truly indicates in the context and is not conductive to promote the diffusion of Chinese culture but also it's likely to causes culture barriers in cross-cultural communication.

4) 董斜川道: “好, 好, 虽然·马前泼水”, 居然“破镜重圆”, 慎明兄将来的婚姻一定合悲欢, 大有可观”(Xiong, 2011, p.167) 
Tung Hsien-chuan said,"well, now. Though 'water was poured before the horse,' still, the 'broken mirror was made round again'. Shen-ming's marriage will certainly be full of vicissitudes. It should be worth watching.” (Xiong, 2011, p.167)

The connotative meaning of the idiom “马前泼水” is that when a couple divorced, they can't reunion with each other and their relationship can't be restored or recovered just like the poured water that cannot be returned. The translator who maintain the metaphorical objects “马” and “水” use literal translation to render this idiom, which maintain the peculiar flavor of the source language. This kind equivalent translation doesn't interpret the connotation and historical background of the idiom, which leads to that information passed on in the idiom are took no notice by target readers. There is historical difference about the idiom, and it's difficult to cross culture barriers and understand the meaning of “马前泼水” (water was poured before the horse) and they may feel confused and doubt why individuals pour water before a horse. It's would be better to translate it into the pieces don't fit any more. Though it sacrifices the peculiar favor of Chinese culture via equivalent translation, it indeed is propitious to dissemination of culture.

5) 怎么的，你倒把好心当作驴肝肺！好，咱们支部会上见。( Du, 2005)

Oho, so you can't tell a man's honest heart from a donkey's liver and lungs? So that how you take my good advice? All right, we'll settle this at the Party branch meeting!

The implication of the idiom is that individuals take one's good will as ill intent, and it literally means that misunderstand a man's ingenuous heart for a donkey's liver and lungs. It not only provides means for the target readers to know more about Chinese culture and to keep the original culture favors as well as to pass on the implication of the idiom and benefit the readers.

2. Compromising translation with abandoning of image

Compromising translation signifies the elimination of implicit image. The author intends to make clear the technique of idioms interpretation and free translation should be applied in rendering. For instance:

1) 这段山路崎岖难行, 老张老马识途, 所以让他带路。(China Daily, 2014)

The road is rugged and winding, so we have Lao Zhang lead the way because an old hand is the best guide.

In the sentence, the animal idiom “老马识途”, whose literal meaning is that old horse knows the way, and it can be rendered experienced guide. This is illustrated by Ye Zinan \& Shi Xiaojing (2001) in their book Introduction to Chinese-English Translation Key Concepts and Techniques. The English idiom "like an old horse" means creature of habit which has different connotation, and it can't be used here. Therefore, translators must watch over false friends.

2) 老实讲, 以前我以为 “三反” 运动是假的, 不过是杀鸡给猴看, 做给别人看的。(Zhou, 2004)

To tell the truth, I've always thought until now that the "three Antis" campaign was sham, making an example of a few to frighten all the rest.

The idiom “杀鸡给猴看” literally refers to kill the chicken to scare the monkey, in which the image "chicken” and "monkey" has been eliminated in the interpretation "making an example of a few to frighten all the rest".

The translator applies liberal translation, which empowers foreign readers to have a correct understand the connotation of this idiom.

3) (他们)都是些狐群狗党! (Cao, 2012)

They're a pack of curs!

In Chinese fox is uncomplimentary, which refers to people who are skeptical and provocative. However, in English fox means to a person who is intelligent and have the capability to win what he longs for by deceiving or manipulating others.

In western culture, the fox is well-known for its brilliance and canny. This is the similar as dog. In Chinese dog has uncomplimentary meaning, while in western culture, individuals invariable reckon dogs as their companions and partners. Therefore, it's quite fastidious for people from foreign countries to understand this idiom. The author applys compromising translation to render it, abandoning the image of "fox" and "dog" to interpret the idiom.

Chinese renowned translator Liu Zhongde put forward the three characters “信达切”(faithfulness, expressive, and closeness) as a principle of interpretation, which is also esteemed as the criterion.

\section{Translation of Metaphorical Vacancies Animal Idioms}

Many animal idioms in the two languages are correspondent in part or completely non-corresponding. In Chinese, there are a multitude of four-character structure animal idioms which are very special in Chinese, because these idioms are invariably closely concord with documented events. Some animals perhaps boast an implicit meaning in certain culture, but it doesn't exist in another culture. On the other hand, a kind of animals may live in a region but they don't exist in another one. That is what we called metaphorical vacancies.

1. Compromising translation and abandoning image

In C-E translation, animal idioms with four-character can't be rigidly translated into four English words, and therefore translators should dig the implication idioms so as to have a accurate and comprehensive perspicacity of connotation of animal idioms. In this sphere, the author maintains that this kind of method, compromising translation and abandoning image, will be best choice. She intends to apply some exemplars to make clear this point.

Compromising translation and abandoning image is a strategy and it adopts a transparent, fluent style, aiming at 
disparaging the peculiarity of source language for target language readers.

2. Take idioms of "鹤” as an example

In English the animal “鹤” is called crane, and many idioms correlate to it in Orient. It doesn't has metaphorical meaning in western culture, while it is widely known in Chinese society that "鹤”, whose English name is crane, signifies longevity, on the ground that cranes can live for several decades, which is very long lifespan to birds. In western people's mind, however, it doesn't arise any connotations like that. Therefore, in translating these idioms, we should abandon the image of "鹤", dig the deep implication of the idioms so that Zielsrache readers can come to realize the implication of idioms and promote mutual communication.

In the process of communication, “别鹤孤变” should be translated as husband and wife having to live far apart from each other; “鹤立鸡群”should be rendered as stand head and shoulders above others; “童颜鹤发” should be translated as healthy in old age; “孤雌寡鹤” usually be translated as of a woman who has lost her spouse; “杳如黄鹤”means leave never to return; “闲云野鹤”refers to carefree and unrestrained people. If we maintain the image of “鹤”, it's different for foreigners to understand what it means. (Hui, 2004, p. 2004)

In the procession of interpretation of animal idioms, translators must notice their connotations and translate them according to concrete matters. The translation of metaphor is includes almost all linguistic translation, because it provides many ways for translators to choose: deliver meaning, or change its implicit objects, or revise animal idioms or to mingle its implication and its implicit objects and so on. The translation idioms intimately correlate with the context.

\section{Points for Attention in Translating Chinese Animal Idioms}

Translator highlights the following points while translating animal idioms. One is doesn't take animals idioms too literally, another is don't translate animal idioms in Orient word-for word.

1. Don't take Chinese animals idioms too literally

On the ground that a great majority of the Chinese animals boast implicit meaning, and Chinese idiom is a phrase that signifies something different from the implication of the respective words from which it is formed. Therefore, literally translation of idioms often leads to serious problems and mistakes in some cases. For example:

The idiom “骑虎难下” doesn't means ride a tiger and come upon it is difficult to get off. And in the process of communication, the animal idiom should be rendered

as hold a wolf by its ears or between the homs of a dilemma.

In translating animal idioms in Orient, having a comprehensive understanding of the meaning is necessary. The animal idiom “管中窥豹” signifies someone have a limited view of something, instead of looking at a leopard through a bamboo tube.

This is the same as “顺手牵羊”, which doesn't means lead away the sheep by the way rather it means walk off with something. It is indispensable that the author needs to know the historical background when interpretation the idiom. In this case, translators must dig the deep implication of the animal idiom.

2. Don't translate Chinese idioms word-for-word

Many Chinese animals idioms bears strong culture flavor, some of which are "four-character expression", which are more vivid, poignant and enthralling.

Since idioms or culture-loaded expressions are peculiar to a language or culture and affirmed by its usage, and merely a few have its correspond idiom, therefore literal translation may bring about the misstatement of original implications of animal idioms.

For instance, the idiom “热锅上的蚂蚁”should not be translated as like a cat on bricks, rather it should be translated as like a cat on hot bricks. On the ground that the first vision is too difficult for foreign reads to understand. The idiom “拦路虎”should be translated as “a lion in the way”, rather than a tiger in the way. The idiom“害群之马”should not be rendered as a black horse, which should be translated as a black sheep.

\section{CONCLUSION}

This paper analyses the slants of translating animal idioms in Orient from the perspective of analogous study of animal idioms. In the progression of animal idioms, four kinds of idioms are discussed: similar implicit objects, same implicit meaning; divergent implicit objects, similar metaphorical meaning; similar metaphorical objects, divergent metaphorical meanings and metaphorical vacancies. According to divergent kinds of animal idioms in Orient, translation slants are cogitated respectively. Moreover, the analogous study of animal idioms is likely to help readers have a comprehensive apprehension of animal idioms as well as the divergences of the two cultures. Meanwhile, numerous examples of animal idioms are given correspondingly to vividly demonstrate each kind of animal idioms. In this paper, the author mainly makes clear how to render animal idioms with same object, and different metaphorical meaning as well as metaphorical vacancies.

The author explains that idioms in Orient, which have same metaphorical objects and different metaphorical meanings, can be interpreted by the consequential ways an equivalent translation, reserve image; b. compromising translation, abandon image. The strategies of compromising translation and abandoning image is used in translate 
metaphorical vacancies animal idioms. The author also mentions what should be paid attention in translation idioms with metaphorical vacancies.

\section{ACKNOWLEDGEMENTS}

A great many people's goodness is engraved on my heart. At first, I am overwhelmed for the kindness of my talented and dedicated professors. Professor Xin Xin has been amiable and benevolent in helping me reexamine this paper. She offers a multitude of invaluable instructions. For instance, I am expected to have my own viewpoints in analyzing the interpretation tactics of animal idioms instead of merely giving a lot of examples. It is very necessary for me to articulate my own perspectives towards animal idiom translation.

When I take linguistic courses, professor He Ali have has given me a great amount of inspiration in writing this paper. When I am in dilemma she has been willing to lend me hands and has always given me many instructions on my paper from the very beginning. Additionally, I'm engraved on my heart to Kong Rui, who teaches us both American and English literature, for she constantly reminds that we should prepare for our thesis in advance. Moreover, she always requires us to read some excellent thesis, and helps us to analysis the structure of a thesis in her class. Their instructions and suggestions are quite beneficial to this paper writing.

In addition, Professor Xin Xin and Professor Kong Rui give me a lot of guidance and invaluable advice in this paper writing. Without their timely instruction, it's impossible for me to fulfill this formidable work in time. Besides, Professor William George and Professor Roger's kindness are engraved on my heart, my oral English teachers. Both of them provide me with valuable foreign websites and excellent e-books, which are of vital paramountcy to the paper writing. They provide me with invaluable information. I am quite grateful for all of my dedicated and kindhearted professors for they take pains to teach me, guide me, and help me.

Furthermore, I bear a debt of gratitude for all my friends, particularly my roommates. They have done great favor in assisting me to search for and gather information. My devout debt especially goes to parental support, enlightenment and fortitude in my four years of pursuit of my study.

\section{REFERENCES}

[1] Cao Xueqin. (2012). https://wenku.baidu.com/view/fdf6e7ef998fcc22bcd10ddc.html(accessed 20/11/2018).

[2] Cao Xueqin. (2012). https://wenku.baidu.com/view/05985dd6c1c708a1284a44fa.html(accessed 21/11/2018).

[3] Cao Xueqin. (2012). http://www.oktranslation.com/Forums/showtopic-9047.aspx (accessed 20/11/2018).

[4] China Daily. (2014). http://www.i21st.cn/translate/contributions/5848/\#dummylink(accessed 20/11/2018).

[5] Deng Yanchan \& Liu Runqing. (1989). Language and Culture. Beijing: Foreign Language Teaching and Research Press.

[6] Du Pengcheng. (2005). https://wenku.baidu.com/view/0426491910a6f524ccbf85c8.html (accessed 20/11/2018).

[7] Hornby, A.S. (1997). Oxford advanced learner's English-Chinese dictionary. Beijing: Beijing The Commercial Press.

[8] Hui Yu. (2004). A New Century Chinese-English Dictionary. Beijing: Foreign Language Teaching and Research Press.

[9] Jeanne Kelly, Nathan K. Mao. (2003). Fortress Besieged. Beijing: Foreign Language Teaching and Research Press.

[10] Liu Yu ping. (2008). English Idioms and their cultural Origin. Tianjin: Nankai University Press.

[11] Smith.L.P. (1957). Words and Idioms: Studies in the English Language. London: Constable and Co Limited.

[12] Xiong Hua. (2011). Cultural Interpretation Based on Cross-culture English Version of the Fortress Besieged. Anhui Literature, $6,167$.

[13] Zeng Meiting. (2007). On the Cultural "Portraiture" of Translation Strategies of animal idioms. Journal of Qiongzhou University, $14,85$.

[14] Zhou Erfu. (2004). https://wenku.baidu.com/view/0426491910a6f524ccbf85c8.html (accessed 20/11/2018).

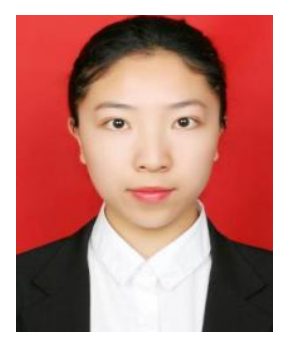

Jili Liu was born in Lvliang, China in 1994. She is pursuing her master's degree in English Translation and Interpretation from Shanxi Normal University, Linfen, China in 2018.

She is currently an apprentice English teacher in Modern College of Arts and Science Shanxi Normal University. Her research interests include English Translation and Interpretation.

Ms. Liu is a member of the Modern College of Arts and Science Shanxi Normal University. 